\title{
How Organizational Culture Affects Employee(s) Work Engagement in the Insurance Industries in Ghana: An Ambidextrous Approach [AAA]
}

\author{
Aphu Elvis Selase ${ }^{1}$, Lu Xinhai $^{1} \&$ Ekor Sophia Enyonam Abla ${ }^{2}$ \\ ${ }^{1}$ College of Public Administration, Huazhong University of Science and Technology, Wuhan, China \\ ${ }^{2}$ College of Public Administration, China University of Geosciences, Wuhan, China \\ Correspondence: Aphu Elvis Selase, College of Public Administration, Huazhong University of Science and \\ Technology, Wuhan 430074, China. Tel: 86-156-2392-7060.
}

Received: September 28, 2018

doi:10.5430/jms.v9n4p22
Accepted: October 10, 2018

Online Published: October 14, 2018

URL: https://doi.org/10.5430/jms.v9n4p22

\begin{abstract}
The study assessed how organizational culture affects employee work engagement in the insurance industries in Ghana. A cross sectional survey design was used to purposively sample one hundred and sixty-one (161) employees from two leading insurance companies ambidextrously. The Pearson Product Moment Correlation and Independent t-test were the statistical tools used to test the three hypotheses of the study. The results of the study revealed that, there is a positive significant relationship between organizational culture and employee work engagement. Again it was established that managers are more likely to be engaged on their job than non-managers and gender has no significant influence on engagement levels. The study therefore concluded that, to increase employee work engagement, organizations must adopt a favorable culture. Therefore we recommend that organizations should maintain and sustain favorable culture in order to increase the level of employees work engagement.
\end{abstract}

Keywords: affects, ambidextrous, culture, employee, engagement, Ghana, insurance, industries, organizational

\section{Introduction}

\subsection{Background of the Study}

Organizational culture has for quite some time been explored into throughout the years. There have been a few investigations into writing to investigate the impacts of authoritative culture on such a large number of factors of which work commitment is of no special case. Culture is a game plan of various traits that express an organization and separate the firm from other one (Forehand and Gilmer, 1964). As indicated by Hofstede (1980), culture is the aggregate reasoning of psyches which make a distinction between the individuals from one gathering from another. According to Schein (1990), characterizes culture as the arrangement of various qualities and practices that might be considered as manual for progress. As per Kotler and Heskett (1992), culture implies genuinely settled arrangement of convictions, practices and estimations of society contain by and large. In straightforward words we can comprehend that culture is picked up learning, clarifications, values, convictions, correspondence and practices of huge gathering of individuals, in the meantime and same place.

Organizational culture as indicated by (Schein, 1985) is the arrangement of convictions, qualities, and presumptions that are shared by individuals from an organization. These basic qualities have an impact on the conduct of authoritative individuals as individuals depend on these qualities to manage their choices and practices. Schein (2003) again characterized hierarchical culture as a dynamic power inside the organization which is spinning, connecting with intuition and it took care of business workers and administration's motions, practices and states of mind. In fact, expanded learning about hierarchical (organizational) culture can give pioneers, directors, and scientists with exceptional knowledge in regards to principal qualities of an association (Schein, 1985), that swing to help in overseeing or changing the way of life.

In the event that an association (organization) does not have workers who are submissive and occupied with the usage and execution of procedures, change will be troublesome if certainly feasible (Saks, 2006). Understanding the conditions under which people effectively draw in, while others withdraw is exceedingly significant for the two workers and managers (Wildermuth and Pauken, 2008). As indicated by Kahn (1992) commitment intends to be mentally present when possessing and playing out a hierarchical job. Rothbard (2001) likewise characterize 
commitment to as mental nearness however goes further to express that it includes two basic part. Consideration and ingestion. Consideration alludes to intellectual accessibility and the measure of time one spends pondering a job while retention implies being immersed in a job and alludes to the power of one's attention on a job.

As (Aphu E. S. 2015) showed, in the event that you infuse time as a remedy in your everyday dealings, you will dependably have solid minutes cum productive outcomes. Thusly, time should be clung to in as much as one is locked in to execute an obligation for an authoritative execution, accomplishments and subsequently exemplifying productivity. (Aphu E.S 2018)

Irvine (2013) expressed that officials are as yet coming up short on understanding what representatives require in the event that they will connect completely in their work and accomplishing the association's goals. He again settled the way that authoritative culture drives worker commitment. As indicated by Deci and Ryan (1987) administration which cultivates a strong workplace commonly shows worry for representatives' needs and sentiments, gives positive input and urge them to voice their worries, grows new abilities and take care of business related issues. Purcell, Kinnie, Hutchinson, Rayton and Swart, (2003) featured that worker commitment is just important if there is a more bona fide sharing of duty among administration and representatives over issues of substance. Their investigation additionally uncovered that inclusion in choices influencing the activity or work to be an imperative factor, which was emphatically connected with elevated amounts of representative commitment in this way showing it is a critical driver. Thus, making a sound authoritative culture that is pleasing to advancing worker commitment is basic for ideal association results.

\subsection{Statement of the Problem}

The test today isn't simply holding gifted individuals, yet completely captivating them, catching their psyches and hearts at each phase of their work lives. Worker commitment has risen as a basic driver of business achievement in the present aggressive commercial center. Further, representative commitment can be a main factor in authoritative achievement (Lockwood, 2007).

Not exclusively does commitment can possibly altogether influence representative maintenance, profitability and reliability, it is additionally a key connect to consumer loyalty, organization notoriety and by and large partner esteem. Therefore, to pick up a focused edge, associations are to set the motivation for worker commitment and responsibility (Lockwood, 2007).

Hierarchical culture is the arrangement of convictions, qualities, and presumptions that are shared by individuals from an association (Schein, 1985). These fundamental qualities have an impact on the conduct of authoritative individuals, as individuals depend on these qualities to control their choices and practices (Schein, 1985). Extrapolating from the impact culture has on the conduct of hierarchical individuals much has been required to be composed about the effect of culture on the workers' commitment.

The association between a worker's commitment and hierarchical culture include understanding the qualities and convictions of the association and how critical the responsibility is to the company's prosperity and in addition it being the most essential driver of representative commitment. Both authoritative culture and work commitment of representatives are in risk when representatives' close to home estimations are incongruent with those of the association. The suggestion that association culture may impact levels of work commitment along these lines conceivably has a broad effect, and the inferred interface between these develops made this an essential relationship to examine and get it

It is of this vulnerability that the specialists dove further into the connection between hierarchical culture and representatives' commitment by investigating both immediate and circuitous impacts and how authoritative culture impacts worker states of mind and those demeanors that influence workers' commitment.

Objectively, the main objective of the study is to assess the effect of organizational culture on employee engagement in some selected organizations in Ghana. The researchers used those selected organizations as a case study. However, the study had the following objectives: To investigate the effect of organizational culture on employee engagement. To examine whether differences exist among managerial and non- managerial employee concerning work engagement. To examine whether male employees are more likely to be engage than female employees.

Hypothetically, there will be a significant relationship between Organizational culture and employee work engagement. Managers are more likely to be engaged on their jobs than non-managers. Male employees are more likely to be engaged on their jobs than female employees. 
Significantly, the outcome of this study is to help in identifying effects of organizational culture on employee engagement as well as help provide leaders with a foundation on which to build a better understanding of the effects of organizational culture on employee engagement.

This study is also important to organizations in Ghana to determine the various factors of organizational culture that influence employee's engagement decisions to enable them adjust their cultures in other to aid the organizations to properly utilize their resources, increase their profitability and growth.

The study of organizational culture is relevant to managers to know how employees behave towards work engagement in organizations of certain cultures. Again, from a managerial point of view, the findings of this study can be used to support managerial decision making both at operational and strategic levels aiming towards improved organizational cultures and commitment of employees.

The outcome of this study help bridge the gap in literature by offering some empirical evidence to the extent of which the result in Ghana would be parallel to past studies.

The result of the study contributes to the body of knowledge by establishing the extent to which employee's engagement are affected by organizational culture and understand why employees make certain engagement decisions.

Furthermore, this study provides a general framework for researchers, policy makers, and professionals a guide for future research studies.

\section{Review of Literature}

\subsection{Introduction}

The survey of theoretical literature review of bringing to the fore the various concepts of organizational culture, gender differences, and its effects on employee work engagement from the perspective of different authors. This is followed by the empirical literature review which is considered as the application of the theories.

\subsection{Theoretical Literature Review}

Organizational Culture correctly characterize the details of authoritative culture. Regardless of no single hypothesis is consistently acknowledged, there is a general assent about hierarchical culture on being customarily decided and socially organized that includes convictions, practices, qualities and ethics aligned with various levels of the association and fuses to all parts of authoritative life (Hofstede, Neuijen, Ohauv and Sanders, 1990; Pettigrew, 1990).

The hypothetical contention about culture is that it is a mind boggling arrangement of standards and qualities that is formed after some time (Schein, 1985). It is by and large comprehended as the social magic that binds organizational individuals and communicates the qualities, social thoughts, and convictions that individuals share. An association's way of life hence, through its qualities and working convictions, applies ordering effects on how its representatives see occasions (Denison and Mishra, 1995) and how they act (Barney, 1986; Schein, 1985).

\subsection{Schein's Three Levels of Organizational Culture (1992)}

Hierarchical culture as indicated by (Schein, 1985) is the arrangement of convictions, qualities, and presumptions that are shared by individuals from an association. He again recognizes that even with thorough examination, we can just make articulation about components of culture not culture completely. Schein (1992) offered an imperative commitment to characterizing hierarchical culture. He isolated authoritative culture into three levels.

These are indicated below;

* Artifacts and behaviors

* Espoused values

* Basic assumptions and beliefs

Ancient rarities are the visual hierarchical structures and procedures. They are the part of the association that can be effortlessly perceived yet hard to get it. Precedents of these curios are offices, disciplines, devices, instruments et cetera. Upheld esteems are the cognizant methodologies, objectives and rationalities of the association. Precedents of which are customs and schedules, legend and stories, perfection et cetera.

Fundamental presumptions are the oblivious underestimated convictions, contemplations and sentiments (extreme wellspring of qualities and activities). They are hard to observe in light of the fact that they exist at a to a great extent oblivious level yet they give the way to understanding why things happen the manner in which they do. 


\subsection{Johnson and Schole's Cultural Web Model (1997)}

The social web is a portrayal of the underestimated suspicions of an association. Johnson and Scholes (1997) allude to a hierarchical worldview involving the kind of presumptions which are infrequently discussed, which are not viewed as hazardous, and about which directors are probably not going to be express. The segments of this worldview mirror the aggregate understanding of the association. Six noteworthy sorts of curio can be distinguished in the model, these are,

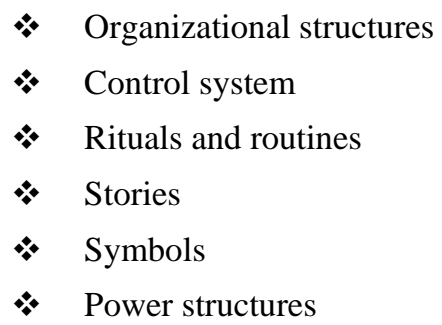

Relics in this setting are the most noticeable and most shallow indications of a hierarchical culture. Worldview (set of suppositions about the association which are underestimated).

Authoritative structure alludes to the way organizations structure their work. It incorporates both formal chain of importance and casual structures. The hierarchical structure is probably going to reflect control structures, outline critical connections and underscore what is essential in the association (Johnson and Scholes, 1997).

Control frameworks show the manners in which that the association is controlled and what is vital to screen in the association, and to concentrate consideration on. These incorporate money related frameworks, quality frameworks, and prizes (counting the manner in which they are estimated and appropriated inside the association).

Customs and schedules: the standard ways that individuals from the association carry on towards one another and towards those outside the association involve "the way we get things done around here". The ceremonies of the association are the unique occasions through which the association underlines what is especially imperative and fortifies "the way we get things done around here" Stories. The past occasions and individuals discussed inside and outside the organization. Who and what the organization deifies says a lot in regards to what it esteems, and sees as awesome conduct.

Images are words, objects, conditions, acts or attributes of people that imply something else or more extensive from themselves, and which have significance for an individual or gathering. They cover a scope of various components logos, titles or the sort of dialect and phrasing ordinarily utilized. It turns into a shorthand portrayal of the idea of the association. Power structures in an association are probably going to be intently connected with groupings (frequently administrative), inside the association which impact the plan and recognition of an arrangement of center suppositions and convictions, since these underlie the "apparent shrewdness" of how to work effectively.

\subsection{Work Engagement}

Kahn (1990) was the first to conceptualize engagement, defining personal engagement as the concurrent manifestation and expression of an individual's ideal self in task behaviors that encourage a connection to work and to others, a connection to personal presence (physical, cognitive, and emotional), and a connection to active, full role performance.

However, according to Salonova and Schaufeli (2011), burnout and engagement are exclusive of one another; individuals undergoing low burnout may not be undergoing high engagement and vice versa, which led Bakker, Gonalez-Romá, Salanova and Schaufeli, (2002) to operationalize work engagement as distinct from burnout.

Work engagement as defined by Schaufeli et al. (2002) is a positive, fulfilling, work-related state of mind that is characterized by vigor, dedication, and absorption. Rather than a momentary and specific state, engagement refers to a more persistent and pervasive affective-cognitive state that is not focused on any particular object, event, individual or behavior.

\subsection{Khan's Psychological Presence Theory (1990)}

Kahn $(1990,1992)$ contended that commitment comes full circle from a state called mental nearness - a state in which the real evident features of oneself can be completely communicated. In this state, people don't have to control their convictions, values, contemplations, emotions, tendencies, and connections. 
Kahn (1990) is much of the time attributed as the principal researcher to apply the idea of commitment to work. Kahn found that there were three mental conditions related with commitment or separation at work: significance, wellbeing, and accessibility. By and large, these three conditions decide if representatives are more drawn in or withdrew (Kahn, 1990).He found that laborers were more connected with at work in circumstances that offered them more mental importance and mental security, and when they were all the more mentally accessible.

Seriousness: he exhibited that representatives encounter a feeling of importance in their work, this nearness or commitment will probably happen. That is, in a few settings, people feel their work identifies with some more extensive, persevering, vital, and attractive target or esteem. They feel their work lines up with the goals they esteem. As an outcome, they turn out to be more disposed to commit their endeavors to this undertaking, as opposed to withhold their effort, which shows as nearness or commitment.

Wellbeing: When people feel that such devotion and application to their job won't come full circle in unfortunate or contrary outcomes, mental security and commitment is additionally more prone to follow (Kahn, 1990). That is, commitment surfaces when representatives feel that issues or afflictions are either impossible or reasonable.

Accessibility: Individuals can keep up this commitment and application to their work just in the event that they can get to the fundamental assets, called mental accessibility. That is, they require, for instance to have the capacity to assemble the essential vitality or effort (Kahn, 1990).

\subsection{Empirical Literature Review}

There are various empirical findings, both from developed and developing countries has recorded mixed results. A number of researchers have noted a positive quantitative relationship between both organisational culture and gender difference and employee work engagement in organisations, while some found the negative relationship.

Naidoo and Martins (2014) embraced an exploration on the theme researching the Relationship between Organizational Culture and Work Engagement in which their discoveries demonstrate a positive connection between every one of the measurement that is hierarchical culture and work commitment individually. Their discoveries again propose that positive impressions of authoritative culture are probably going to be identified with larger amounts of work commitment. The examination again calls attention to that authoritative culture is a key thought in understanding work commitment.

Their investigation utilized a quantitative methodology with an example size of 455 out of an ICT organization. The inspecting system utilized is a proportionate arbitrary stratified testing. This investigation utilized connection and relapse in computing the entomb connection among both reliant and autonomous factors. The South African social instrument was utilized to gauge hierarchical culture whiles the utretch work commitment scale was utilized to quantify work commitment of which the two was score on a 5 likert scale. The examination did not investigate the impact of subgroup contrasts identified with age, sexual orientation, status, and so on yet our investigation investigated the impact in contrasts among sex and positions, and utilized purposive inspecting and accommodation testing system.

Research by Muntaha, Lewis and Syed (2013) on the theme is work commitment gendered? The examination depended on survey of a few literary works identified with work commitment. The investigation turned out to state that work commitment is a gendered idea as it is simpler for men to exhibit work commitment than ladies. The examination clarify advance that the three mental conditions by Khan (1990) that prompted work commitment are additionally gendered where ladies need to conquer authoritative obstructions to encounter these condition. The investigation showed that in view of authoritative structure, hierarchical culture and belief system, it is less demanding for men to exhibit work commitment than ladies.

Saks (2006) attempted an exploration on the theme predecessors and results of representative commitment in which an overview was finished by 102 workers working in an assortment of employments and associations. The normal age was 34 and 60 percent were female. Members had been in their present place of employment for a normal of four years, in their association a normal of five years, and had by and large 12 years of work involvement. The study included proportions of employment and association commitment and also the precursors and outcomes of commitment. The outcomes demonstrate that there is a significant distinction among occupation and association commitment and that apparent authoritative help predicts both employment and association commitment; work qualities predicts work commitment; and procedural equity predicts association commitment. What's more, occupation and association commitment intervened the connections between the precursors and employment fulfilment, authoritative duty, expectations to stop, and hierarchical citizenship conduct. 
David and Pandey (2013) with the subject what drives representative commitment explored what work qualities prompts high worker commitment. The instrument utilized contains fourteen things related with various measurements of worker commitment. Information was gathered through purposive examining from 107 respondents on five point likert scale through poll. The unwavering quality of poll was broke down utilizing SPSS (Statistical Product and Service Solutions). Additionally factor examination with VARIMAX pivot utilizing Kaiser Normalization was connected to the information which brought about three components. Discoveries of the investigation recommends that agreeable workplace, chances to develop and work enhancement prompts higher commitment in representatives having a place with quickly developing ventures like it and pharma. All respondent have a place with age gathering of $20-40$ and $90 \%$ of them are beneath 30 . Which additionally recommend significance of these elements in drawing in gen $\mathrm{x}$ representatives in these enterprises.

An examination led by Rieger, Roodt and Sempane, (2002) on the point work fulfilment in connection to authoritative culture which planned to set up whether a relationship existed between the factors work fulfilment and hierarchical culture of representatives inside an administration association. The populace involved 200 workers of which 40 were avoided from the examination because of poor education levels. A culture and Minnesota work fulfilment surveys were directed to the example of 160 representatives and 121 usable reactions were gotten. High coefficient alphas were acquired on both the hierarchical culture survey (OCQ) $(0,99)$ and the Minnesota work fulfilment poll (MJSQ) $(0,92)$. Huge contrasts were found between some true to life factors and reactions on the OCQ. A critical relationship was found between scores of the OCQ and the MJSQ.

Johari, Rashid and Sambasivan (2003) in their paper with the theme the impact of corporate culture and authoritative duty on execution inspected the impact of corporate culture and hierarchical responsibility on money related execution in Malaysian organizations. An organized survey was created and self-regulated to supervisors in Malaysian organizations. An aggregate of 202 directors out in the open recorded organizations took part in the examination. The outcomes demonstrate that there is a noteworthy relationship between's corporate culture and hierarchical responsibility. Both corporate culture compose and hierarchical responsibility have an impact on the money related execution of these organizations.

Once more, Rahman, Rashid and Sambasivan (2004) in a theme the impact of authoritative culture on states of mind toward hierarchical change explored the impact of authoritative culture on demeanours toward authoritative change in Malaysia. An organized survey was created and self-regulated to 258 organizations recorded in the league of Malaysian assembling catalog. In the example, about 65 percent of the aggregate respondents were male and the rest were female. Around 41 percent of the aggregate respondents were Malays, 46 percent were Chinese, and 9.7 percent were Indians. As far as age gathering, almost 62 percent of the respondents were between 31-50 years of age, 23 percent were beneath 30 years of age, and 13.6 percent were over 50 years of age. As far as instructive foundation, almost 75 percent had tertiary training (four year certification or proportional). As for work position, 22.9 percent of the respondents were CEOs, 26.4 percent were general directors, and 30.2 percent were human asset administrators.

A five-point interim scale was utilized to quantify every one of the reactions. The respondents were requested to demonstrate their reactions running from 1 (emphatically concur) to 5 (firmly oppose this idea). The inside consistency (Cronbach's alpha) for solidarity measurement and friendliness measurement of authoritative culture were 0.8895 and 0.8309 , individually. The Cronbach's alpha coefficient for hierarchical culture for the 23 things was 0.7157. Information were dissected utilizing the Statistical Product and Service Solutions (SPSS) for windows programming. Enlightening insights, which incorporate frequencies and rates, were used to introduce the principle attributes of the example and the profile of hierarchical culture and states of mind toward authoritative change. Cross-classification and chi-square examination were additionally utilized to quantify the relationship between the factors. The outcomes demonstrated that there is a relationship between authoritative culture and the full of feeling, subjective, and conduct inclination of mentalities toward hierarchical change. The discoveries likewise demonstrated that distinctive kinds of authoritative culture have diverse levels of acknowledgment of states of mind toward hierarchical change. This implies certain sort of authoritative culture could encourage the worthiness of progress, while different kinds of culture couldn't acknowledge it.

As Aphu E.S \& Adator S.W indicated, the challenges of SMEs have been a major limitation to fulfilling the expected goal as a backbone of any economy. This implies that, SMEs also have employees in as much as their engagement to the work assigned them is the focal point thereby contributing positively or negatively to the economy based on their inputs.

Shakil (2012) in a theme Impact of authoritative culture on execution Management hones in Pakistan Aimed to grow the base of information and exactly test the connection between parts of hierarchical culture and execution 
administration rehearses. The examination embraced exploratory research to investigate the effect. Essential Data was gathered through surveys from 60 representatives in COMSATS foundation of data innovation. The example comprises of both male and female employees. Relapse and connection investigation was utilized for measurable examination. The measurable Results demonstrate that inclusion is very associated with consistency and flexibility. So also, different measurements of hierarchical Culture have essentially positive association with the execution administration hones. The examination chose test from couple of urban communities of Pakistan. Future examinations could choose different urban areas and contrast results and city of chose test. The examination utilized Random testing methodology, which is the principle restriction of this investigation. Future examinations could utilize stratified arbitrary testing system with more example estimate.

Alfes, Truss, Soane, Rees and Gatenby (2010) in their examination, making a drew in workforce: discoveries from the Kingston representative commitment consortium venture found that ladies are essentially more connected with in general than men: while $74 \%$ of ladies announced being modestly drawn in and $9 \%$ emphatically drew in, $68 \%$ of men are reasonably connected with and $7 \%$ firmly locked in. They set up that supervisors are fundamentally more connected with than non-directors and when all is said in done, they found that those in proficient or administrative jobs are the most engaged.

Agyemang and Ofei (2013) embraced an exploration on the subject "Worker work commitment and authoritative responsibility: a near investigation of private and open segment associations in Ghana". The examination researched worker work commitment and authoritative duty utilizing a similar methodology of private and open part representatives in Ghana. They purposively inspected one hundred and five (105) workers of three open and three private associations with comparable to qualities in the Accra city of Ghana. Four speculations was tried. Pearson item minute connection and autonomous t-test was the factual instruments utilized in investigating the information they gathered. The discoveries of their examination uncovered a huge positive connection between worker commitment and representative responsibility. Workers of private associations have a more elevated amount of representative commitment and hierarchical duty than representatives out in the open associations, and since quite a while ago tenured and short-tenured representatives did not contrast in responsibility levels.

Their study points out the need for employees to be provided with resources needed to perform their work roles since it has consequential effects on employee engagement and organizational commitment. The study compared private and public sector employees in relation to employee work engagement has an independent variable in addition to organizational commitment but in our study employee work engagement is a dependent variable to organization culture and not using the comparative approach.

Aphu E.S et al (2017) given the structure of the Ghanaian economy, higher growth in the agricultural sector is needed to fuel growth in other sectors. The size of the sector indicates that, agriculture could be the engine for a more rapid growth and poverty reduction. The insurance industry is likewise part of the above mentioned sectors Selase en co referred to in its generality. Climate variability is a disincentive to agricultural investment prompting the risk-averse farmer to take precautionary strategies that buffer against climatic extremes. Aphu E.S et al, (2017) Therefore, more engagement in agriculture is likewise required not only the insurance industry.

\section{Methodology - Case Study Approach}

This this portion discusses how the research study was undertaken and also outline methods used by the researchers in achieving their objectives. It also highlighted on the design of the study, population, sample frame and sampling technique used as well as instruments and data collection procedures.

This research used a quantitative research approach. This is because quantitative research is a research design that allows objective theories to be tested by examining the relationship among variables. The scope of the work was based on a cross sectional design. This enabled the researchers to provide quantitative description of trends, attitudes or opinions of a population by studying a sample of it. A cross-sectional research design was used to collect data on relevant variables at a time from a variety of people or phenomenon.

Our study was limited to 2 selected insurance companies in the capital city of Greater Accra region. The study consisted of 161 respondents from the selected companies at different positions and both sexes.

A non-probability sampling method was used. Precisely purposive techniques was used in selecting the companies for the study whiles Convenience sampling was used in selecting the sample elements that were readily available to participate in the study and who can provide the required information. Due to the busy schedule of the companies, convenience sampling was most appropriate. 
The research data was from a primary source. The selected respondents were given self-administered questionnaires to fill. It took about two months to retrieve back one hundred and sixty one (161) filled questionnaires out of two hundred (200) questionnaires issued. The questionnaires were divided into three parts.

The first part covered respondents' demographic data such as gender, position and educational background. The second part covered their perception about organizational culture as compared to their jobs adopted from Organizational Culture Assessment Questionnaire (OCAQ) by Sashkin and Rosenbach (2013). The 5 items questionnaires were scored on a 5 point likert scale ranging from strongly disagree (1) to strongly agree (5). The third part covered the work engagement. The Utrecht Work Engagement Scale (UWES) by Schaufeli et al. (2002) was adapted. The instrument consist of 7 items, which was scored on a 5 point likert scale ranging from strongly agree (1) to strongly disagree (5).

Data gathered was coded and entered into Statistical Product and Service Solutions (SPSS) Software. Hypothesis one was tested by analyzing the data collected using Pearson product-moment correlation statistical tool in determining the relationship between the two variables.

Hypothesis two was tested by analyzing the data collected using Independent t-test in establishing the differences in the employee work engagement with respect to positions and hypothesis three was to find the extent to which males and females are compared in predicting employee work engagement so Independent $t$-test was suitable for analyzing the data collected in testing of that.

\section{Results and Discussions}

\subsection{Introduction}

This arena presents and discusses the data collected from the field in line with the objectives and research questions set in chapter one. It analyses the data and attempts to bring the statistical meanings out and discuss the findings of the study. It presents the use of descriptive method of statistical analysis in arriving at the objectives of the study. The presentation of the result of the study begins with an examination of the demographic characteristics of the respondents, followed by the display and brief description of the statistical tables and figures that proffering solutions to the research objectives and questions. All analyses were done with the aid of Statistical Product and Service Solutions (SPSS) at a $95 \%$ confidence interval.

\subsection{Demographic Characteristics}

Table 1. Summary of demographic characteristics

\begin{tabular}{lll}
\hline Demographic Characteristics & N & Percentages \% \\
\hline Sex & 70 & 43.5 \\
Male & 91 & 56.5 \\
Female & & \\
Age & 94 & 58.4 \\
$18-35$ & 67 & 41.6 \\
36 and Above & & \\
Educational Level & 10 & 6.2 \\
Diploma & 26 & 16.1 \\
Higher National Diploma & 91 & 56.6 \\
Degree & 32 & 19.9 \\
Masters & 2 & 1.2 \\
Doctorate & & \\
Position & 84 & 52.2 \\
Non-Managerial & 77 & 47.8 \\
Managerial & & \\
Length of Service & & \\
\hline
\end{tabular}


Less Than 3 Years

3 Years and Above
49

112
30.4

69.6

Total Number of Respondents $(N=161)$

Source: Field data, August 2018

Table 1 shows the frequency and the percentage distribution of the gender, age, educational level, position and length of service of the respondent of the study. The study involved more females than males as it can be seen in the table above. From the table, it shows that 70 respondent were males which represent $43.5 \%$ and 91 of the respondent were females which also represent $56.5 \%$. Gender is one important factor that is perceived to have different and diverse views about the variables. From the numbers and percentages it has been realized that in Ghana females are more interested in the insurance industry than males because of its service nature, it is much of interpersonal relationships, communication and customer relation.

The ages of employee are perhaps relevant is assessing their perception about organizational culture and employee work engagement. Views in respect of the variables may vary for employees in different age groups. From the table, 94 of the respondents were aged between 18-35 years which represent $58.4 \%$ of the total respondent and 67 of the respondent were aged 36 years above which represent $41.6 \%$ of the total respondents. The age distribution is observed that majority of the respondents were in the ages of 18-35.

Educational background may be a factor which the researchers suspected could affect the views of the respondents. From the table, 10 of the respondents were diploma holders depicting 6.2\%, 26 of the respondents were higher national diploma holders representing $16.1 \%, 91$ of the respondent were degree holders in percentage as $56.6 \%, 32$ of the employees holding masters were involved indicating $19.9 \%$ of the total respondent and 2 doctorate holders were also involved representing $1.2 \%$. It is observed from the percentages that greater number of the respondents were degree holders which established the fact that the industry employ more graduates for their operations because of their knowledge in-depth and high competence level relatively. It is perceived that workers with high education have high expectations on their jobs.

The positions of the employees is assumed to have effect on the views about the variables. From the table, 84 of the respondents were of non-managerial positions which is $52.2 \%$ and 77 of the respondent were holding managerial positions depicting $47.8 \%$ of the total respondent. This shows there were more response from non-managers than manager(s).

From the table, it is indicated that 49 of the employees had been working for period of less than 3 years representing $30.4 \%$ and 112 of the respondents were employees who have worked with their organizations for a period of 3 years and more. It is seen that majority of the respondents have worked for their organizations for a period of 3 years and more. This can be as a result of employees becoming comfortable with their current job and would not like to change environment or organizations having better conditions to retain worker because of their experience other than going in for new workers. The responses may be influenced by the length of service of the respondents.

\subsection{Hypotheses Testing}

\section{- Testing Hypothesis One}

The first hypothesis was to investigate the extent to which organizational culture is related with employee work engagement. This hypothesis was investigated using Pearson product-moment correlation coefficient. Summary of the results are presented in Table 2 below

Table 2. Pearson product-moment correlation between organizational culture and employee work engagement

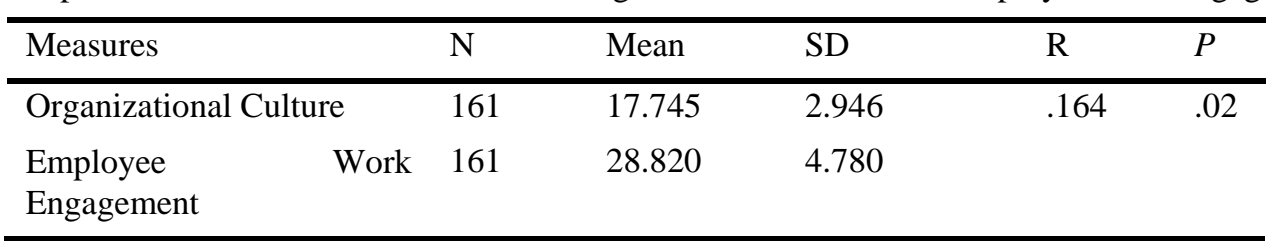

Source: Field data, August 2018 
From Table 2 above, there is a significant positive relationship between organizational culture and employee work engagement $[r=164, p<0.05]$.

\section{- Testing Hypothesis Two}

The second hypothesis examined differences in the employee work engagement scores with respect to positions. Independents t-test was used to test the hypothesis. Summary of the results are presented in Table 3 below.

Table 3. An independent t-test table showing the difference between non-managerial staff and managerial staff on the perception of employee work engagement

\begin{tabular}{|c|c|c|c|c|c|c|c|c|}
\hline & & Position & $\mathrm{N}$ & Mean & SD & $\mathrm{df}$ & $\mathrm{t}$ & $P$ \\
\hline \multirow{2}{*}{$\begin{array}{l}\text { Employee } \\
\text { Engagement }\end{array}$} & Work & Non-Managerial & 84 & 28.202 & 4.979 & 159 & -1.723 & .04 \\
\hline & & Managerial & 77 & 29.489 & 4.489 & & & \\
\hline
\end{tabular}

Source: Field data, August 2018

From table 3 above, managers (mean=29.4886, $\mathrm{SD}=4.48865$ ) are significantly more engaged on their jobs than non-managers (mean=28.2024, $\mathrm{SD}=4.97894)$. Therefore the hypothesis which stated that "Managers are more likely to be engaged on their jobs than non-managers." was supported. $(\mathrm{t}=-1.723, \mathrm{p}<0.05)$

\section{- Testing Hypothesis Three}

Hypothesis three examined the extent to which males and females are compared in predicting employee work engagement. Summary of the results are presented in Table 4 below.

Table 4. An independent $t$ test table showing the difference between males and females on the perception of employee work engagement

\begin{tabular}{|c|c|c|c|c|c|c|c|c|}
\hline & & Sex & $\mathrm{N}$ & Mean & SD & df & $\mathrm{t}$ & $P$ \\
\hline \multirow{2}{*}{$\begin{array}{l}\text { Employee } \\
\text { Engagement }\end{array}$} & Work & Male & 70 & 29.143 & 4.414 & 159 & .776 & .23 \\
\hline & & Female & 91 & 28.571 & 5.053 & & & \\
\hline
\end{tabular}

Source: Field data, August 2018

From Table 4 above, males are not significantly more engaged on their jobs than females. Therefore the hypothesis that "Male employees are more likely to be engaged on their jobs than female employees" is not supported by the analysis $[t=0.776, p>0.05]$.

\subsection{Discussion}

- Organizational Culture and Employee Work Engagement

The main aim of this study was to find the effect(s) of organizational culture on employee work engagement. The result obtained after the analyses indicated that the first hypothesis that is there is a significant relationship between organizational culture and employee work engagement was supported. This finding shows that the level of employees being more engaged on their jobs and the organization's culture are significantly related and organizational culture then has much influence on employee work engagement in the Ghanaian setting. The finding agrees with the result of a research on the topic investigating the Relationship between Organizational Culture and Work Engagement undertook by Naidoo and Martins (2014) in which their findings indicate that positive perceptions of organizational culture are likely to be related to higher levels of work engagement and organizational culture is a key consideration in understanding work engagement. The finding of this study is also in agreement with a research conducted by Rieger, Roodt and Sempane, (2002) on the topic job satisfaction in relation to organizational culture which established a positive relationship existed between the variables job satisfaction and organizational culture of employees within a service organization. 
Schein's three levels of organizational culture (1992) and Khan's psychological presence theory (1990) explain the finding. That is the three levels of organizational culture which are artifacts and behaviors, Espoused values and Basic assumptions and beliefs with the three psychological conditions related with engagement or disengagement at work which are meaningfulness, safety, and availability. Collectively, these three conditions determine whether employees are more engaged or disengaged (Kahn, 1990). In the perspective of our environment or setting the organizations with more favorable assumptions, beliefs and value which assures it employees a better conditions of service and the psychological conditions (meaningfulness, safety and availably) have more committed and high level of employee work engagement. Organizations in Ghana are much concern in the welfare and the living of their employees which has been incorporated into the culture of most organizations enhancing employees to be committed and increase their level of engagement since they find it comfortable and motivating to go the extra mile when performing their duties.

\section{- $\quad$ Position and Employee Work Engagement}

Again the study found that, Managers are significantly more likely to be engaged on their jobs than non-managers. The result supported the second hypothesis that Managers are more likely to be engaged on their jobs than non-managers. This finding is consistent with David and Pandey (2013) result on the topic what drives employee engagement, investigated what job characteristics leads to high employee engagement and findings of the study suggests that satisfactory work environment, opportunities to grow and job enrichment leads to higher engagement in employees. Again this result is in connection with Alfes, Truss, Soane, Rees and Gatenby (2010) in their research, creating an engaged workforce: findings from the Kingston employee engagement consortium project, established that managers are significantly more engaged than non-managers and in general, they found that those in professional or managerial roles are the most engaged.

The finding can be explained with the Khan's Psychological Presence theory that the three psychological conditions related with engagement or disengagement at work: meaningfulness, safety, and availability indicate workers are more engaged at work in situations that offered them more psychological meaningfulness and psychological safety, and when they were more psychologically available. In the Ghanaian working environment, employees with higher positions or in the upper offices experience more of the three psychological conditions which encourage managers to be more committed to their jobs than non-managers.

Also managers may be more involved in decision-making processes within their organizations and experience greater autonomy than non-managers, which may explain why their engagement levels are significantly higher. Again employees with managerial positions are much offered several incentives and various packages which enchant them to be more engaging with their jobs compared to that of worker of lower positions. Another dimension for the outcome of the study in our environment is because of the perception that much is expected from workers with high positions. Higher positions come with some benefit and the same positions has its work load, responsibilities and duties which take more commitment and dedication on the part of the employee in accomplishing and executing the designated jobs. Also the cliché "a leaders should live an exemplary life for their followers to emulate", this has also have some positive effect on the minds of employee with higher positions which induce them to be more engaging on their jobs. All these factors have been the force behind the high engagement level of managers in relation to non-managers in the Ghanaian setting.

\section{- $\quad$ Gender and Employee Work Engagement}

The study has established that gender has no significant positive relationship with employee work engagement. The result turned not to support the third hypothesis that males are more likely to be more engage on their jobs than females. Therefore this implies that being a male or female does not influence or affect an employee from being more engage on their job in the Ghanaian working environment. This finding disagrees with the research by Muntaha, Lewis and Syed (2013) on the topic 'is work engagement gendered?'.Their study came out to say that work engagement is a gendered concept as it is easier for men to demonstrate work engagement than women. Alfes, Truss, Soane, Rees and Gatenby (2010) in their research, creating an engaged workforce: findings from the Kingston employee engagement consortium project found some interesting variations which is in relation with this result. They discovered that women are significantly more engaged overall than men: while $74 \%$ of women reported being moderately engaged and $9 \%$ strongly engaged, $68 \%$ of men are moderately engaged and $7 \%$ strongly engaged.

The result is explained that the three psychological conditions that led to work engagement are not gendered where women and men are all entitled to experience these conditions. Therefore if employees are offered more psychological meaningfulness, psychological safety and when they are more psychologically available in perspective of being a male or female is reasonably enough for worker (both males and females) to be more committed. One 
possible reason for this outcome is of the saying "women can do what men can do and even better". It has been realized that this saying is having some great reflections on the commitment levels of females in the Ghanaian setting. Previously, the local culture of most Ghanaian prevented females from having professional and formal jobs. Females were expected to be at home taking care of house duties and the total welfare of the house and not to be engaged to white color jobs. The number of educated females was even limited which hindered them from being recognized in terms of former occupations. But the coin has turn recently, more females are encouraged to attain formal education and professional occupations which has enabled equality in relations to males. Most females are recently ambitious and achievement driven triggering their development for success. This development among females has influence their level of commitment and dedication to their jobs which increase their level of engagement to bridge the gap between males and female in connection to work engagement. Therefore, there is no significant difference in gender about employee work engagement as the findings established using the Ghanaian environment for the study.

\section{Conclusion and Recommendations}

\subsection{Introduction}

This arena presents a summary of the major findings, conclusion based on the findings of the study, implications and the recommendations for further research.

\subsection{Summary}

Findings revealed that there exists a significant and positive relationship between organizational culture and employee work engagement. This implies that the more favorable the culture of the organizations are, the higher the engagement level of the employees. It was pointed out that, organizational culture is a major factor to consider when thinking about employee work engagement in our environment.

In the quest of the researchers to identify the engagement levels of employees, the study revealed that managers are highly engaged on their jobs than non-managers are, which indicate that, positions of employees influence the engagement levels of employees. The study also pointed out that there are no significant difference in the engagement level in terms of sex. This means that, sex do not influence the level of engagement of employees.

\subsection{Conclusion}

The study seeks to assess the effects of organizational culture on employee work engagement in Ghana using two selected insurance companies ambidextrously in the capital city as a case. To understand the research issues raised in the study and to place the relevant literature in context, as well as to generalize the study to some extent, a thorough review of the literature was made.

The study found that the culture of an organization has emerged as a critical driver and a deciding factor of employee work engagement. Thus, the organizations must consider improving their cultures when setting agenda for employee engagement and commitment. The Khan's psychological presence theory explained that workers are more engaged at work in situations that offered them more psychological meaningfulness and psychological safety, and when they were more psychologically available, therefore if the cultures of organizations are made favorable, employee work engagement level will be high.

Also, the study confirmed that Managers are significantly more likely to be engaged on their jobs than non-managers. It pointed out that employee with managerial position are much offered several incentives and various packages which enchant them to be more engaging with their jobs and also their psychological conditions are better off compared to that of worker(s) of lower positions

The findings further revealed that gender has no significant positive relationship with employee work engagement. This shows how gender inequalities have been reduced in recent times enhancing females to match males in the working environment.

In nutshell, a general conclusion can be made that there exists a positive significant relationship between organizational culture and employee work engagement. This relationship is enhanced by the influence of organizational culture on employee work engagement based on the presence of the needed psychological conditions by the Khan's psychological presence theory, therefore for an organization to keep its employees engaged in their various assigned duties, it must take into consideration the culture of the organization and implement flexible structures and systems. 


\subsection{Recommendations for Future Studies}

In this investigation, the variable (organizational culture) was the main supporter towards representative work commitment; additionally inquire about, thus could be investigated in different determinants of worker work commitment or if there are different factors that should be joined with this variable so as to animate and enhance representative work commitment in Ghana.

Additionally, in the examination both open and private associations were consolidated in the investigations yet there are a few contrasts in culture among open associations and private associations, a near report should be possible to set up level of commitment between workers of open associations and private associations. It is prescribed that future research could utilize diverse strategy crosswise over numerous associations in the nation.

\subsection{Implications for Theory and Practice}

The examination helps in writing by offering some exact proof(s) in the foundation of the connection between organizational culture and worker work commitment. Hypothetically, the aftereffect of the examination add to the assemblage of learning of which levels of worker commitment are influenced by authoritative culture and the comprehension of representatives settling on certain commitment choices.

Despite the fact that this research went for testing theory hypothetically, the discoveries of the exploration do have a commonsense ramifications for administration and representatives. In light of the discoveries of this investigation, organizations ought to give representatives acceptable workplace, adaptable structures and make spaces for creative thoughts keeping in mind the end goal to expand the level of worker work commitment. As Khan's mental nearness hypothesis recommends, commitment finishes from a state called mental nearness and that there are three mental conditions identified with commitment and withdrawal at work which is significance security and accessibility. Organizations ought to in this way audit their way of life that will influence representatives to accomplish the three mental conditions which will impact worker to build their commitment level since the investigation has demonstrated that there is certain huge connection between authoritative culture and representative work commitment.

\section{Competing Interests}

There is absolutely no competing interests in as much as the collaborative efforts injected into this manuscript by the authors are concerned.

\section{References}

Agyemang, C. B., \& Ofei, S. B. (2013). Employee work engagement and organizational commitment: a comparative study of private and public sector organizations in Ghana. European Journal of Business and Innovation Research, 1(4), 20-33.

Alfes, K., Truss, T., Soane, E. C., Rees, C., \& Gatenby, M. (2010). Creating an Engaged Workforce: Findings From the Kingston Employee Engagement Consortium Project. London: Chartered Institute of Personnel and Development.

Aphu, E. S. (2015). The Study of Time Management in Civil Service Institutions in Ghana: A Case of Accra Metropolitan Assembly. European Journal of Business and Management, 7(30).

Aphu, E. S. (2018). The Impact of Recruitment and Selection Criteria on Organizational Performance. GN Bank, Greater Accra Region of Ghana as the Mirror. Journal of Public Administration and Governance, 8(3).

Aphu, E. S., \& Adator, S. W. (2018). Challenges and Sustainable Development of Small and Medium-Sized Enterprises: Evidence from a Local Processing Company in Ghana (Nkulenu). Advances in Social Sciences Research Journal. https://doi.org/10.14738/assrj.55.4572

Bakker, A. B., \& Demerouti, E. (2007). The Job Demands-Resources Model: State Of The Art. Journal of Managerial Psychology, 22, 309-328. https://doi.org/10.1108/02683940710733115

Barney, J. B. (1986). Organizational culture: can it be a source of sustained competitive advantage. Academy of Management Review, 11, 656-658. https://doi.org/10.5465/amr.1986.4306261

David, S., \& Pandey, S. (2013). A Study of Engagement at Work: What Drives Employee Engagement. European Journal of Commerce and Management Research, 2(7), 155-161.

Deci, E. L., \& Ryan, R. M. (1987). The Support of Autonomy and the Control of Behavior. Journal of Personality and Social Psychology, 53, 1024-1037. https://doi.org/10.1037/0022-3514.53.6.1024

Denison, D. R. (1990). Corporate Culture and Organizational Effectiveness. New York: Wiley. 
Denison, D. R. (2000). Organizational Culture: Can It Be a Key Lever for Driving Organizational Change. The Handbook of Organizational Culture. London: John Wiley \& Sons.

Denison, D. R., \& Mishra, A. K. (1995). Toward a Theory of Organizational Culture and Effectiveness. Organizational Science, 6(2), 204-223. https://doi.org/10.1287/orsc.6.2.204

Forehand, G. A., \& Gilmer, V. (1964). Environmental Variations in Studies of Organizational Behavior. Psychological Bulletin, 62, 361-382. https://doi.org/10.1037/h0045960

Hofstede, G. (1980). Culture's Consequences: International Differences in Work Related Issues. Beverly Hills, CA: Sage.

Hofstede, G. (1980). Motivation, Leadership and Organization: Do American Theories Apply Abroad. Organizational Dynamics, 9(1), 42-63. https://doi.org/10.1016/0090-2616(80)90013-3

Hofstede, G., Neuijen, B., Ohayv, D., \& Sanders, G. (1990). Measuring Organizational Cultures: A Qualitative and Quantitative Study across Twenty Cases. Administrative Science Quarterly, 35, 289-316. https://doi.org/10.2307/2393392

Irvine, D. (2013). Culture Drives Employee Engagement, Not the Other Way Around. HRM Today Social Network, 1, $18-24$.

Johnson, G., Scholes, K., \& Whittington, R. (1997). Exploring Corporate Strategy. Harlow; Pearson education limited

Kahn, W. A. (1990). Psychological Conditions of Personal Engagement and Disengagement at Work. Academy of Management Journal, 33(4), 692-724.

Kahn, W. A. (1992). To Be Fully There: Psychological Presence At Work. Human Relations, 45, 321-349. https://doi.org/10.1177/001872679204500402

Kotter, E. H., \& Heskett, O. K. (1992). Culture: The Missing Concept in Organizational Studies. Administrative Science Quarterly, 4(2), 229-240.

Kotter, J. P., \& Heskett, J. L. (1992). Corporate Culture and Performance. New York, NY: The Free Press.

Lockwood, N. R. (2007). Leveraging Employee Engagement for Competitive Advantage: HR's Strategic Role. Alexandria: Society for Human Resource Management.

Martins, E. C., \& Terblanche, F. (2003). Building Organizational Culture that Stimulates Creativity and Innovation. European Journal of Innovation Management, 6(1), 64-74. https://doi.org/10.1108/14601060310456337

Martins, E., Martins, N., \& Terblanche, F. (2004). An organizational culture model to stimulate creativity and innovation in a university library. Advances in Library Administration and Organization, 2, 83-130. https://doi.org/10.1016/S0732-0671(04)21003-3

Maslach, C., \& Leiter, M. (1997). The Truth about Burnout. San Francisco: Jossey-Bass.

Maslach, C., Schaufelli, W. B., \& Leiter, M. P. (2001). Job Burnout. Annual Review of Psychology, 52, 397-422. https://doi.org/10.1146/annurev.psych.52.1.397

May, D. R., Gilson, R. L., \& Harter, L. M. (2004). The psychological conditions of meaningfulness, safety and availability and the engagement of the human spirit at work. Journal of Occupational and Organizational Psychology, 77, 11-37. https://doi.org/10.1348/096317904322915892

Meyer, J. P., \& Allen, N. J. (1991). A Three Component Conceptualization of Organizational Commitment. Human Resource Management Review, 1, 61-89. https://doi.org/10.1016/1053-4822(91)90011-Z

Muntaha, B., Lewis, P., \& Syed, J. (2013). "Is work engagement gendered?" Gender in Management. An International Journal, 28(7), 400-423. https://doi.org/10.1108/GM-01-2013-0005

Naidoo, P., \& Martins, N. (2014). Investigating the relationship between organizational culture and work engagement. Problems and Perspectives in Management, 12(4), 433-476.

Peters, T. J., \& Waterman, R. H. (1982). In search of excellence: Lessons from America's best-run companies. New York, NY: Harper and Row.

Pettigrew, A. M. (1990). Is Corporate Culture Manageable?. In Wilson, D., \& Rosenfeld, R. (Eds.), Managing Organizations, 12(5), 267-272. 
Purcell, J., Kinnie, N., Hutchinson, S., Rayton, B., \& Swart, J. (2003). Understanding the People and Performance Link: Unlocking the Black Box. London: CIPD

Rahman, A. A., Rashid, M. Z. A., \& Sambasivan, M. (2004). The Influence of Organizational Culture on Attitudes toward Organizational Change. Leadership \& Organization Development Journal, 25(2), 161-179. https://doi.org/10.1108/01437730410521831

Rashid, M. Z. A., Sambasivan, M., \& Johari, J. (2003). The Influence of Corporate Culture and Organizational Commitment on Performance. Journal of Management Development, 22(8), $708-728$. https://doi.org/10.1108/02621710310487873

Rothbard, N. P. (2001). Enriching or Depleting? The Dynamics of Engagement in Work and Family Roles. Administrative Science Quarterly, 46, 655-684. https://doi.org/10.2307/3094827

Saks, A. M. (2006). Antecedents and Consequences of Employee Engagement. Journal of Managerial Psychology, 21(6), 600-619. https://doi.org/10.1108/02683940610690169

Sashkin, M., \& Rosenbach, W. E. (2013). Organizational Culture Assessment Questionnaire. Seabrook, MD: Ducochon Press.

Aphu E.S et al, (2017). Climate Variability: Cocoa Farmers Perception and Coping Strategies, Suaman District of Ghana as the Focal Point. Environment Pollution and Climate Change. 1: 141. 10.4172/2573-458X.1000141

Schaufeli, W. B., \& Bakker, A. B. (2004). Job Demands, Job Resources, and Their Relationship with Burnout and Engagement: A Multi-Sample Study. Journal of Organizational Behavior, 25, 293-315. https://doi.org/10.1002/job.248

Schaufeli, W. B., Salanova, M., Gonzalez-Roma, V., \& Bakker, A. B. (2002). The Measurement of Engagement and Burnout: A Two Sample Confirmatory Factor Analytic Approach. Journal of Happiness Studies, 3, 71-92. https://doi.org/10.1023/A:1015630930326

Schein, E. H. (1985). Organizational Culture and Leadership: A Dynamic View. San Francisco, CA, Jossey-Bass.

Schein, E. H. (1990). Organizational Culture. American Psychologist, 45(2), 109-119. https://doi.org/10.1037/0003-066X.45.2.109

Schein, E. H. (1992). Organizational Culture and Leadership (3rd ed.). San Francisco, CA. Jossey-Bass.

Schein, E. M. (2003). Organizational Culture and Leadership. San Francisco, CA: Jossey-Bass.

Schneider, B., \& Smith, D. B. (2004). Personality and Organizational Culture. Mahwah, New Jersey: Lawrence Erlbaum Associates.

Selase, A. E., Xinhai, L., \& Worlanyo, A. S. (2017). Combination Effects of Opportunity International Savings and Loans Credit Facility on Maize Production and Health: Evidence of Techiman Municipality in Ghana. J Agri Sci Food Res, 8, 196.

Sempane, M. E., Rieger, H. S., \& Roodt. G. (2002). Job Satisfaction and Organizational Culture. SA Journal of Industrial Psychology, 28(2), 23-30. https://doi.org/10.4102/sajip.v28i2.49

Shakil A. M. (2012). Impact of Organizational Culture on Performance Management Practices in Pakistan. Business Intelligence Journal, 5(1), 767-772.

Wildermuth, C., \& Pauken, P. D. (2008). A perfect match: Decoding employee engagement - Part II: Engaging jobs and individuals. Industrial and Commercial Training, 40, 206-210. https://doi.org/10.1108/00197850810876253 